\title{
Comparison of Symbiotic Bacterial Community of Soft Corals Sarcophyton and Sinularia of the Hainan Province, (South China Sea, China)
}

\author{
Hao Lu $^{1,2, \#}$, Alireza Asem ${ }^{1, \#}$, Lu Wang $^{3}$, Weidong Li ${ }^{4, *}\left(\mathbb{D}\right.$, PeiZheng Wang ${ }^{5}$ \\ ${ }^{1}$ Hainan Tropical Ocean University, College of Fisheries and Life Science, 572000 Sanya, China. \\ ${ }^{2}$ Hainan University, College of Ocean, 570228 Haikou, China. \\ ${ }^{3}$ Jiangsu Provincial Freshwater Fisheries Research Institute, 210000 Nanjing, China. \\ ${ }^{4}$ Hainan University, College of Ecology and Environment, Haikou, China. \\ ${ }^{5}$ Hainan Tropical Ocean University, College of Ecology and Environment, Sanya, China. \\ "These authors contributed equally to this work.
}

\section{Article History}

Received 27 October 2020

Accepted 29 November 2020

First Online 30 November 2020

\section{Corresponding Author}

Tel.: +86089866213606

E-mail: 542148880@qq.com

\section{Keywords}

Sarcophyton

Sinularia

16S rRNA

Microbiome

Soft corals

\begin{abstract}
Changes in the microbial community associated with environmental impacts can lead to opportunistic infections, coral disease and death. Diversity analysis and community comparison were performed on 23 collected soft Coral specimens from South China See surrounding Hainan Province (China) based on Illumina MiSeq sequencing. The results showed that Proteobacteria was the main symbiotic bacteria in soft corals. In the same geographical location, the diversity and abundance of symbiotic bacteria in the genus Sinularia are higher than genus Sarcophyton. Unlike Sinularia, the genus Sarcophyton is more inclined to Tenericutes. Furthermore, the same coral species has different bacterial community structure in different environments. The temperature difference between sampling points at $2{ }^{\circ} \mathrm{C}$ is the main factor affecting the results. A large number of Endozoicomonas found in stone corals have not become the dominant bacteria associated with soft corals. Coral-related pathogenic bacteria were not found in this investigation. This study provided a baseline for future studies of soft coral microbiomes, and assessment of functions of host metabolites and soft coral holobionts. Our result documented that same coral species in each locality represent identical pattern of bacterial diversity and community
\end{abstract}

\section{Introduction}

Alcyonacea is an order of Coelenterata, Anthozoa, and Octocorallia. The sea area near Hainan Island is rich in soft coral resources, and their symbiotic microbes have become an important target for the study of marine natural products (Hassan et al., 2019). Symbiotic microorganisms play an important role in driving the nutritional transformation and community succession of coral reef ecosystems and provide new ideas for scientists to develop new marine drugs (Sang et al., 2019).

As an important part of the symbiotic microbial system, symbiotic bacteria play a key role in the material cycle (Lesser et al., 2004), energy flow (Mao-Jones et al.,
2010), and healthy growth of coral ecosystems (Mahmoud \& Kalendar, 2016). During coral bleaching, some nitrogen-fixing bacteria in mucus can replace the algae to feed coral organisms. For example, Oculinary patagonica in the Mediterranean Sea can synthesize organic matter and supply coral tissue to help corals survive during the crisis of lost zooxanthella (Teplitski \& Ritchie, 2009). Moreover, probiotics can also promote the ecological balance of flora in or around the host (Merrifield et al., 2010). The coral symbiotic bacteria community is a complex dynamic combination, and this complex community structure is susceptible to many factors. Regional differences, eutrophication, diseases (Rosenberg et al., 2009) and other driving forces can lead to changes in coral symbiotic microbial community 
structure. For example, McKew et al. (2012) found that the same species of corals in the Caribbean and Indonesian seas have different commensal bacterial community, and the diversity and abundance of symbiotic bacteria are significantly different. Thurber et al. (2009) pointed out that temperature, dissolved organic carbon content, and acidity can affect the symbiotic bacterial community structure of corals. Furthermore, the composition of the coral symbiotic bacteria is affected by environmental factors. Thus, the structure of the coral symbiotic bacteria community can better elucidate the growth condition of the corals. In a study of coral symbiotic bacteria under healthy and bleached conditions, Yu et al. (2019) found that some pathogens (Vibrio, Pseudospirilum, Alteromonas, and Coxiella) are present in albino individuals at high rates. Guest et al. (2016) pointed out that the breaking of the balance of microbial structure would increase the susceptibility of corals to disease, as well as the stability of the community or the biomarker that indicates the risk of bleaching.

Environmental factors can alter relationships among coral hosts and its bacterial community. Neulinger et al. (2008) suggested there was no indicative dissimilarly between the bacterial communities of deepsea stony coral Lophelia from different localities. In contrast, bacterial diversity of Porites and Acropora from two geographical localities in Caribbean Sea (Mexico) and Indo-Pacific (Indonesia) were significantly different (McKew et al. 2012). Additionally, samples of soft coral Scleronephthya gracillimum from different geographically sites represented distinguished differentiation in bacterial diversity (Seonock et al. 2017). It is evident that environmental factors can alter the diversity structure of bacteria at different geographical areas.

Based on high throughput sequencing of extender, which has been widely used in the study of microbial diversity of coral symbiosis, more microbial groups have been found. Liang et al. (2017) obtained a highthroughput sequencing library of $16 \mathrm{~S}$ rRNA gene to analyze the bacterial community structure of various massive and dendritic corals collected from the Xinyi Reef in the Nansha Islands of the South China Sea. They obtained the symbiotic bacteria database of the Nansha reef-building corals in China. The commensal bacterial species have their own preferences in terms of their choice of corals to inhabit (Liang et al., 2017). In this study, the bacterial community structures of $23 \mathrm{soft}$ coral samples collected from Ganzhe island $\left(18^{\circ} 45^{\circ} \mathrm{N}\right.$, $\left.110^{\circ} 30^{\circ} \mathrm{E}\right)$, Dazhou Island $\left(18^{\circ} 40^{\circ} \mathrm{N}, 110^{\circ} 28^{\circ} \mathrm{E}\right)$, and Ximao Island $\left(18^{\circ} 15^{\circ} \mathrm{N}, 109^{\circ} 22^{\prime} \mathrm{E}\right)$ were analyzed by $16 \mathrm{~s}$ rRNA gene high throughput sequencing. Although bacterial community of stony coral have been studied well, there is a lack of information about soft coral. This study performed to explore the diversity of bacterial community with different localities from South China Sea (Hainan Province coral reefs, China) in two common host soft corals genera (Sarcophyton and Sinularia). The main aim is to investigate diversity of symbiotic bacterial associated with localities and coral species.

\section{Materials and Methods}

\section{Coral Collection}

23 soft coral specimens of Sinularia and Sacoprhyton were collected from the coral reef areas in Ganzhe Island (18 $45^{\prime} 31.21^{\prime \prime N}$; $\left.110^{\circ} 29^{\prime} 56.98^{\prime \prime E}\right)$, Dazhou Island $\left(18^{\circ} 40^{\prime} 43.87^{\prime \prime} \mathrm{N}\right.$; $\left.110^{\circ} 28^{\prime} 45.68^{\prime \prime} \mathrm{E}\right)$, and Ximao Island $\left(18^{\circ} 14^{\prime} 9.03^{\prime \prime} \mathrm{N} ; 109^{\circ} 22^{\prime} 27.06^{\prime \prime E}\right)$ (Figure 1). The sampling distance was more than 10 meters, and three samples were collected per individual. The collected specimens were washed with aseptic seawater and placed in aseptic plastic bags. All specimens were stored briefly at low temperature $\left(0^{\circ} \mathrm{C}-4{ }^{\circ} \mathrm{C}\right)$ until laboratory DNA extraction. The coral species were identified in laboratory and compared with bone needles and $\mathrm{COI}+$ igr1+ msh1 barcode (Zhou et al., 2019). Species information is shown in Table 1.

\section{DNA Extraction}

The crown tissue of Sarcophyton $(2.5 \times 2.5 \mathrm{~cm})$ and finger tissue of Sinularia $(2-3 \mathrm{~cm})$ were cut with a pair of scissors. The total DNA (about $50 \mathrm{mg}$, including tissue and mucus) was extracted from marine animal genomic DNA extraction kit (Tsingke, Guangzhou, China). The

Table 1. Coral species list in this study

\begin{tabular}{|c|c|c|c|c|c|}
\hline Location & Total No & Genus & Species & No & Abb. \\
\hline \multirow{3}{*}{ Ximao Island (XI) } & \multirow{4}{*}{6} & Sarcophyton & S. trocheliophorum & 3 & XI_Satr01; XI_Satr02; XI_Satr03 \\
\hline & & \multirow{2}{*}{ Sinularia } & S. grandilobata & 2 & XI_Sigr01; XI_Sigr02 \\
\hline & & & S. querciformis & 1 & XI_Siqu03 \\
\hline \multirow{4}{*}{ Ganzhe Island (GI) } & & & S. crassum & 1 & GI_Sacr04 \\
\hline & \multirow{3}{*}{8} & Sarcophyton & S. glaucum & 2 & GI_Sagl05; GI_Sagl09 \\
\hline & & & S. cherbonnieri & 2 & GI_Sach06; GI_Sach10 \\
\hline & & Sinularia & S. wanannensis & 3 & GI_Siwa-̄10; GI_Siwa 11 ; GI_Siwa12 \\
\hline \multirow{5}{*}{ Dazhou Island (DI) } & \multirow{5}{*}{9} & & S. ehrenbergi & 2 & DI_Saeh0̄7; DI_Saeh1̄1 \\
\hline & & Sarcophyton & S. crassum & 1 & DI_Sacr08 \\
\hline & & & S. maxima & 2 & DI_Sima 0̄4; DI_Sima06 \\
\hline & & Sinularia & S. humilis & 1 & DI_Sihu05 \\
\hline & & & S. querciformis & 3 & DI_Siqu07; DI_Siqu08; DI_Siqu09 \\
\hline
\end{tabular}



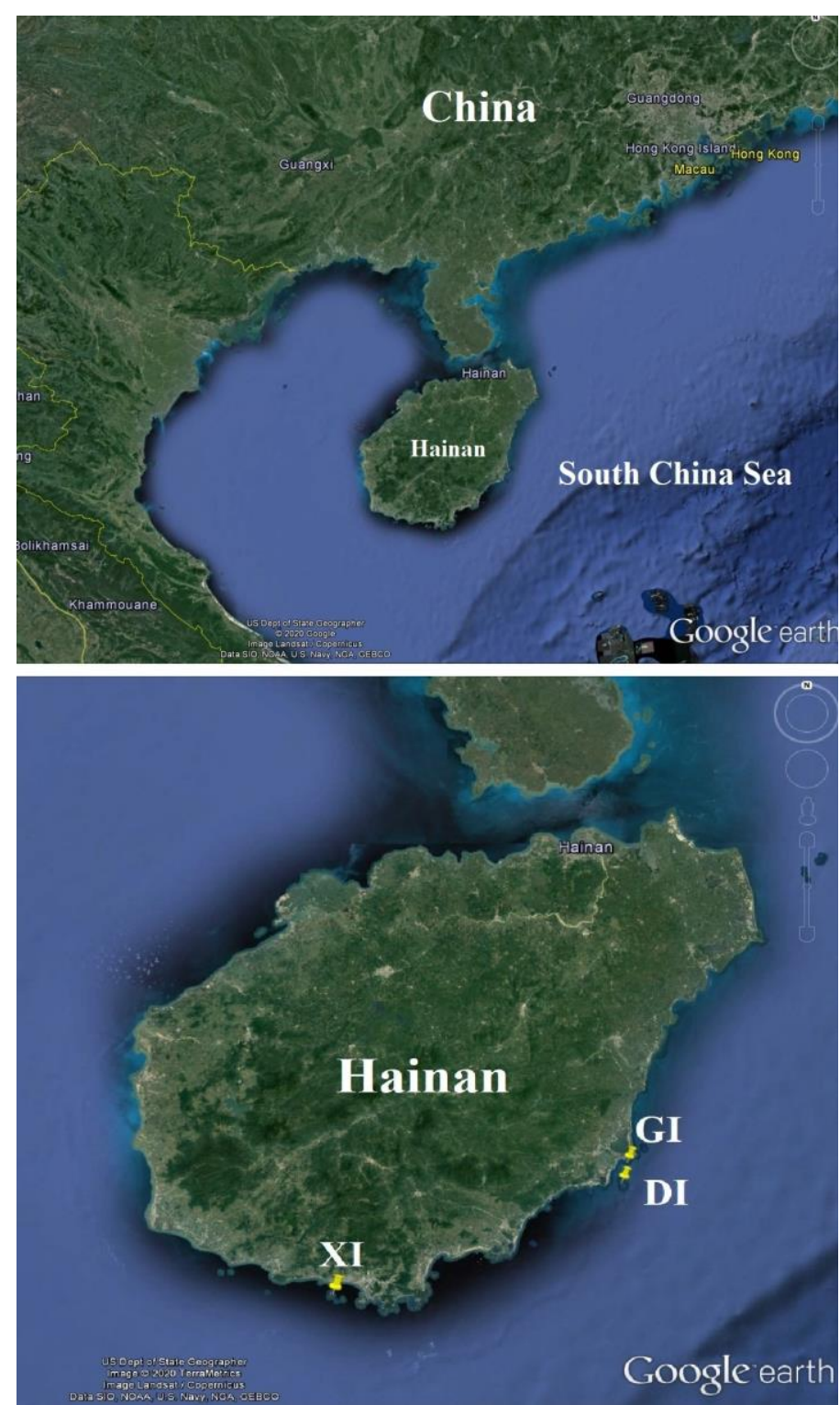

Figure 1. Sample collection location. Ganzhe Island (GI), Dazhou Island (DI), and Ximao Island (XI). Map data (C2020 Google.

instructions on the kit were strictly followed. The prepared DNA is stored at $-80^{\circ} \mathrm{C}$ after quality detection.

\section{PCR Amplification and Illumina MiSeq Sequencing}

Using DNA as template, the V3-V4 variable region of bacterial 16SrRNA gene was amplified by PCR with forward primer 338F(5'-ACTCCTACGGGAGGCAGCAG-3') and reverse primer 806R(5'GGACTACHVGGGTWTCTAAT-3') (Mori et al., 2014; Xu et al., 2016). PCR was carried out in a total volume of $50 \mu \mathrm{l}$ containing $48 \mu \mathrm{l}$ Taq polymerase (2x Easy Taq $^{\circledR}$ PCR SuperMix, Code\#AS111 +dye, TransGen Biotech CO., Ltd. CHN), $1 \mu$ l solution of DNA and $0.5 \mu$ of each primer. PCR amplification was carried out following Liang et al (2017). The quality of PCR products were considered using $2 \%$ agarose gel and it was purified by Gel extraction kit (Axygen Scientific, Inc; CA, USA) following its instruction manual before sequencing. Finally, the duplicate samples were combined and the PE2 $\times 300$ library was constructed according to the standard operating procedures of the Illumina MiSeq platform. Sequencing was performed on the Illumina Miseq PE300 platform (Majorbio, Shanghai, China).

\section{Data Analysis}

According to the method of Liang et al. (2017), raw dataset were standardized using the software Trimmomatic v.0.39 (Bolger et al., 2014) to eliminate the reads with low quality and homopolymer inserts $(<20)$. The remaining high-quality sequences were subjected to OTU cluster analysis and taxonomic analysis utilizing the RDP (Ribosomal Database Project) by USEARCH (UPARSE) (Woo et al., 2017). Based on the results of OTU cluster analysis, the diversity of single specimen (Alpha diversity) was obtained by Alpha diversity index analysis of sample clustering results by software Mothur version v.1.30.1with 1000 iterations (Schloss et al., 2011). The coverage, abundance, and diversity of microbial 
community were reflected by Good's species coverage (Coverage), community richness (Ace), and community diversity (Shannon) index. Taxonomy was identified and compared via SILVA database (Quast et al., 2013) following Qiime platform. Additionally, the Principal Coordinate Analysis (PCOA) was performed using the beta diversity index the OTUs level (Liang et al., 2017).

\section{Results}

Twenty-three specimen raw reads were obtained by high throughput sequencing, with a total of 1175650 valid sequences. The effective sequences of each specimen were more than 27000 , and the length of the sequences was 421-460 bp. The coverage index for all specimen databases was greater than $99 \%$, and the sequencing results accurately reflected the true flora of the specimens. The specimen alpha-diversity index was listed in Table 2.

The average OTU number of genus Sinularia in both Ximao Island and Ganzhe Island was significantly higher than that of genus Sarcophyton, and the average OTU number of genus Sinularia in Dazhou Island was slightly lower than that of genus Sarcophyton. Nine specimens had OTU numbers greater than 500 , of which six specimens were from genus Sinularia and three from genus Sarcophyton. On the contrary, less than 300 OTU samples were from the genus genus Sarcophyton. The values of Shannon index of all specimens were between 1.24 and 5.10 which the GI_Sagl09 specimen and the XI_Sigr02 specimen were respectively the minimum and maximum values. The difference of the large numerical value indicated a great difference in the diversity of the symbiotic bacteria in different specimens. The difference of community richness ACE index between specimens was about the same as that of the Shannon index, except for a few cases such as the XI_Satr02 and XI_Satr03 specimens.

A total of 46 bacterial phyla were detected in 23 examined coral specimens which 24 bacterial phyla were shared among all coral hosts (Figure 2). The dominant phyla of all specimens were Proteobacteria (39.99\%), Tendericutes (22.35\%), Firmicutes (14.13\%), Bacteroidetes (9.58\%) and Acinetobacteria (8.29\%) (Figure 3). After cluster analysis of each specimen, the abundance of symbiotic Proteobacteria was found to be the highest in the genus Sinularia from Dazhou Island. Its abundance was more than $60 \%$ (Figure 4). The specimen with the highest abundance was Si06 (92.8\%). Proteobacteria was detected in other specimens, and the minimum abundance was still more than $10 \%$. Unlike the genus Sinularia, the symbiotic bacteria of the Sarcophyton genus were more abundant. In addition to the large number of Proteobacteria, Bacteroidetes were maintained at a higher abundance (more than 30\%) in the three specimens of the Sarcophyton genus from Ximao Island. The remaining nine specimens of genus Sarcophyton were rich in Tenericutes. In addition, Cyanobacteria were also found in all specimens, and their abundance was the highest in the DI_Saeh07 specimens (13.5\%).

At the class level (Figure 5), Mollicutes, Gammaproteobacteria, and Alphaproteobacteria were the most abundant in all specimens. Among them, Mollicutes was more abundant in the genus Sarcophyton than genus Sinularia, whereas

Table 2. Numbers of sequences, operational taxonomic units (OTUs) (97\%) and diversity estimates of bacteria associated with different corals

\begin{tabular}{|c|c|c|c|c|c|c|c|}
\hline Location & Abb. & No. of. Seq & OTUs & ACE & Chao & Coverage & Shannon \\
\hline \multirow[t]{6}{*}{ Ximao Island } & XI_Satr01 & 36530 & 478 & 591.26 & 591.06 & 0.996304 & 3.55 \\
\hline & XI_Satr02 & 33589 & 344 & 435.80 & 459.12 & 0.997023 & 3.49 \\
\hline & XI_Satr03 & 47633 & 356 & 471.77 & 469.29 & 0.997733 & 3.08 \\
\hline & XI_Sigr01 & 43586 & 866 & 892.66 & 913.63 & 0.998555 & 4.94 \\
\hline & XI_Sigr02 & 35024 & 942 & 972.04 & 987.02 & 0.997887 & 5.10 \\
\hline & XI_Siqu03 & 83226 & 659 & 681.71 & 696.14 & 0.999519 & 5.03 \\
\hline \multirow[t]{8}{*}{ Ganzhe Island } & GI_Sacr04 & 72077 & 279 & 290.18 & 289.91 & 0.999778 & 3.00 \\
\hline & GI_Sagl05 & 77683 & 324 & 333.60 & 347.75 & 0.999743 & 2.70 \\
\hline & GI_Sach06 & 88922 & 324 & 332.75 & 347.75 & 0.999775 & 2.02 \\
\hline & GI_Sagl09 & 41178 & 220 & 230.54 & 239.00 & 0.999514 & 1.24 \\
\hline & GI_Sach10 & 74655 & 352 & 356.14 & 358.00 & 0.999826 & 2.29 \\
\hline & GI_Siwa10 & 77457 & 518 & 528.61 & 528.00 & 0.999793 & 5.01 \\
\hline & GI_Siwa11 & 58289 & 392 & 397.96 & 401.75 & 0.999777 & 4.35 \\
\hline & GI_Siwa12 & 31863 & 309 & 324.56 & 337.88 & 0.999310 & 4.73 \\
\hline \multirow[t]{9}{*}{ Dazhou Island } & DI_Saeh07 & 58289 & 520 & 553.43 & 567.53 & 0.999262 & 3.61 \\
\hline & DI_Sacr08 & 54505 & 648 & 658.70 & 660.83 & 0.999596 & 4.92 \\
\hline & DI_Saeh11 & 27271 & 495 & 504.33 & 512.65 & 0.999083 & 4.06 \\
\hline & DI_Sima04 & 33513 & 548 & 674.00 & 641.44 & 0.995554 & 2.93 \\
\hline & DI_Sihu05 & 36534 & 424 & 583.70 & 593.03 & 0.995867 & 2.74 \\
\hline & DI_Sima06 & 37338 & 398 & 499.86 & 501.71 & 0.996759 & 2.50 \\
\hline & DI_Siqu07 & 32416 & 587 & 639.41 & 646.07 & 0.997100 & 3.06 \\
\hline & DI_Siqu08 & 43343 & 450 & 482.38 & 498.89 & 0.998639 & 2.85 \\
\hline & DI_Siqu09 & 50729 & 606 & 629.26 & 651.23 & 0.999034 & 3.89 \\
\hline
\end{tabular}




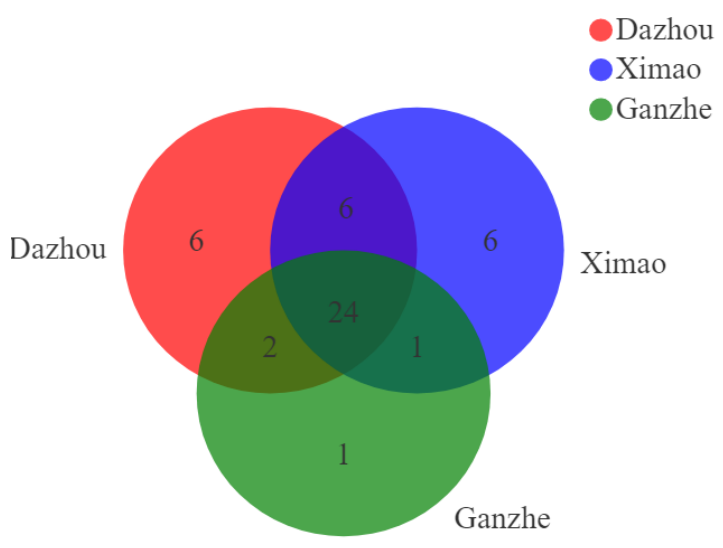

Figure 2. Venn diagram analysis. Different colors represent different groups (differnet islands), overlapping parts represent unique phyla in multiple groups (differnet islands), no overlapping parts represent phyla specific to the grouping (differnet islands), and numbers represent the corresponding number of phyla.

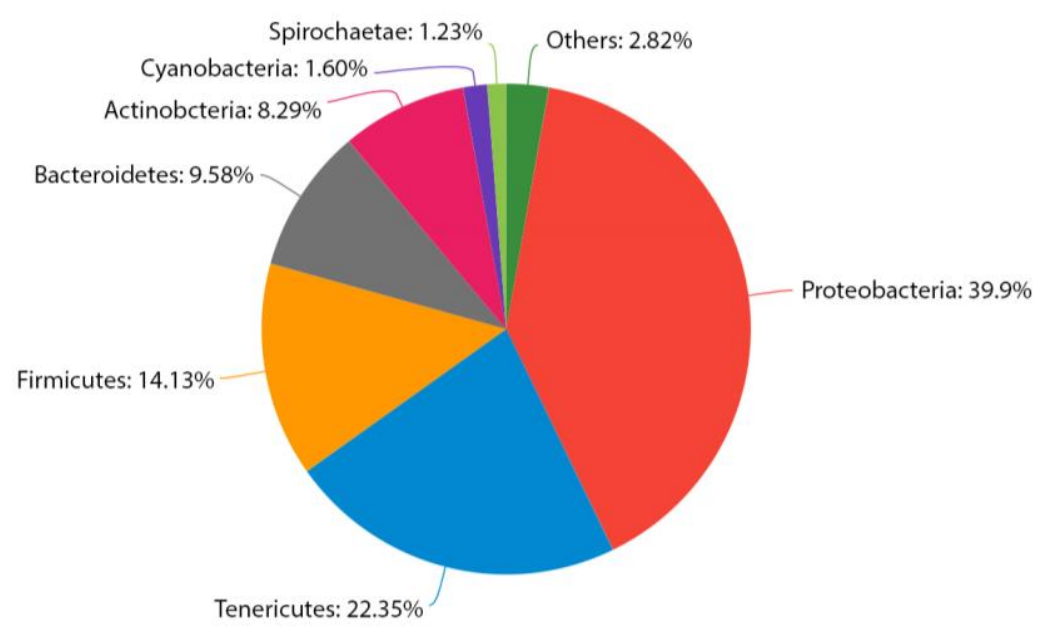

Figure 3. Microbial commiunity pieplot on phylum level: All samples. "others" represent the bacterial phyla with abundances of less than $0.01 \%$.

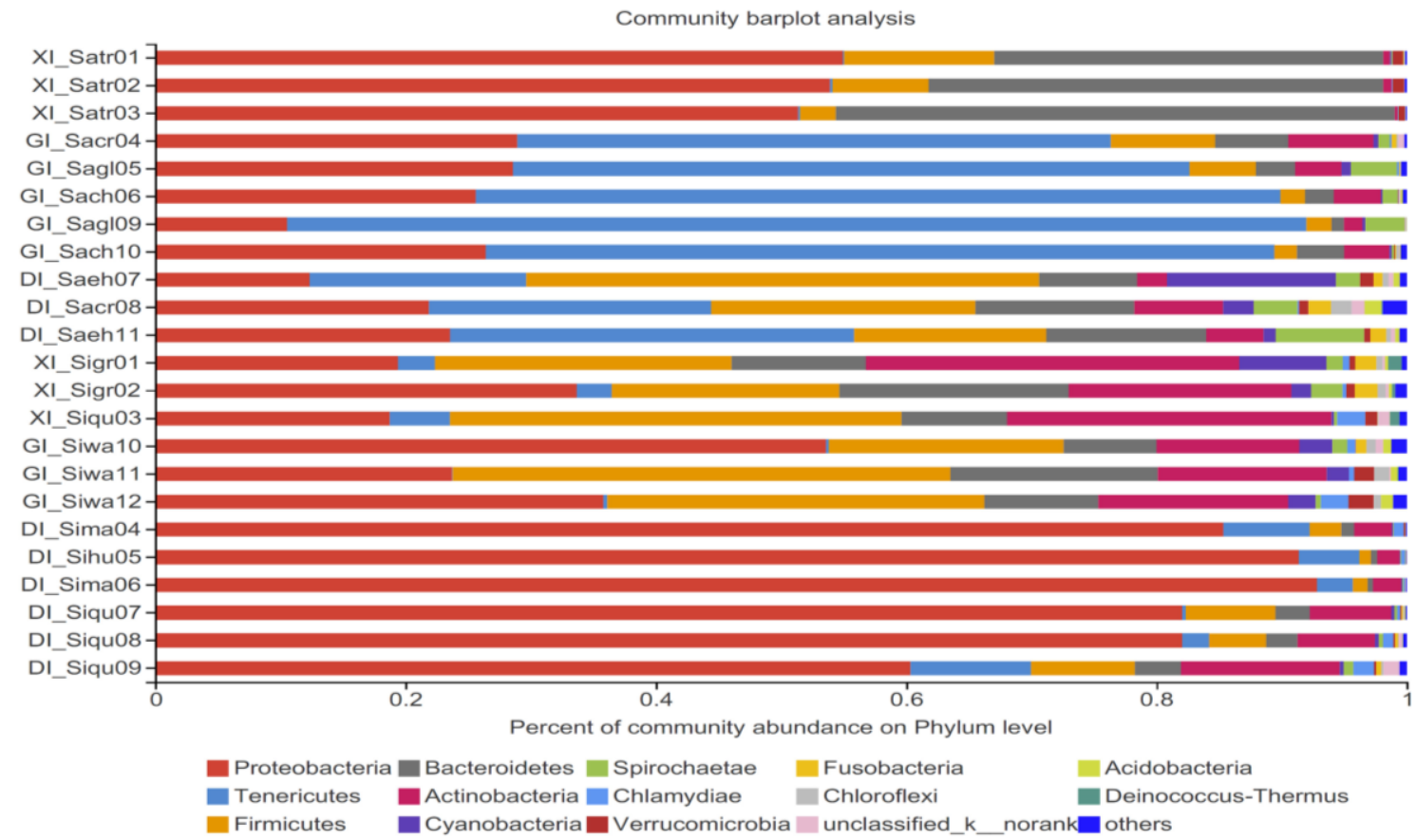

Figure 4. Bacterial composition profiles. Taxonomic classification of bacterial reads retrieved from different coral species on phylum level. "others" represent the bacterial phyla with abundances of less than $0.01 \%$. 


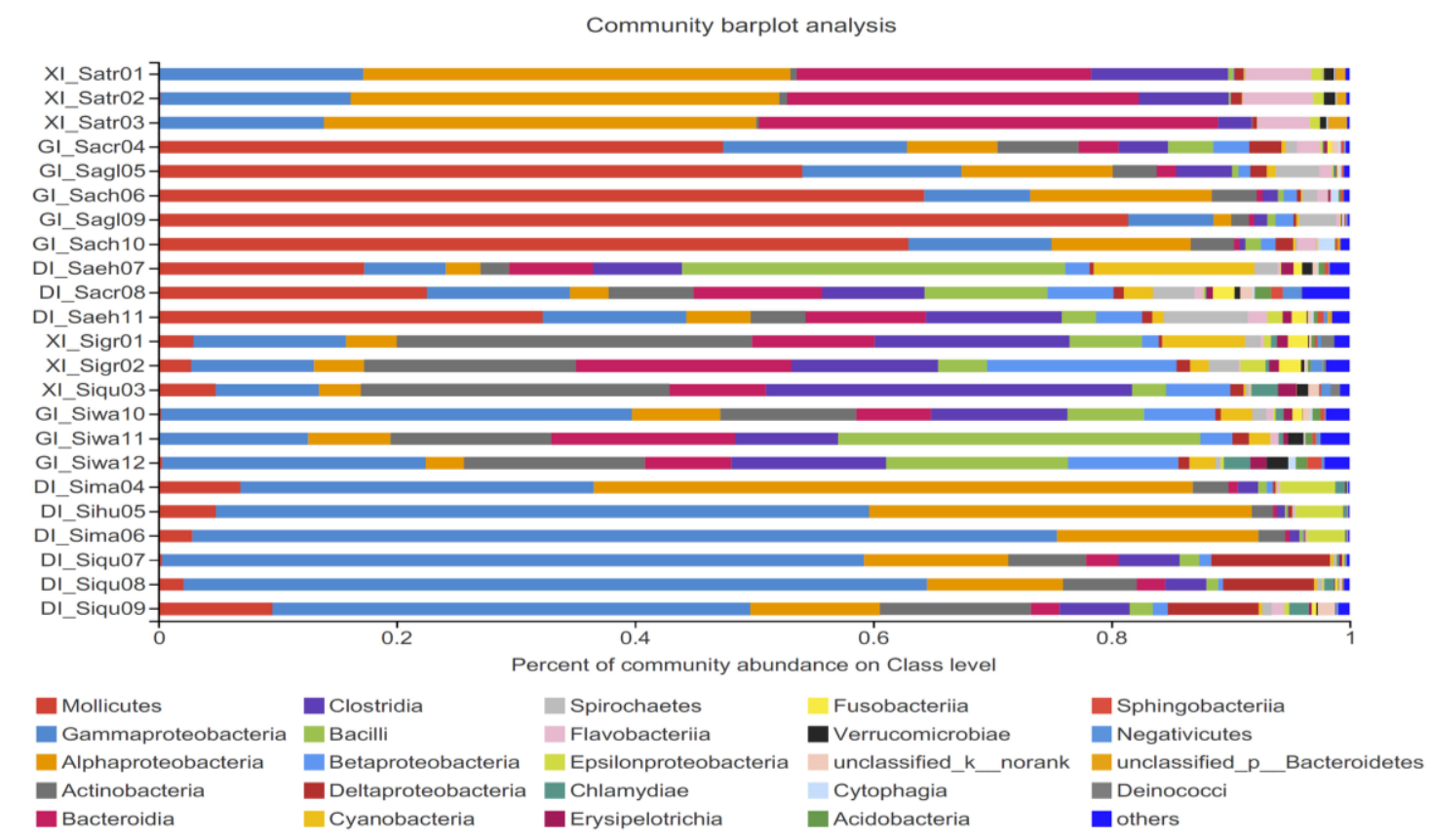

Figure 5. Bacterial composition profiles. Taxonomic classification of bacterial reads retrieved from different coral species on Class level. "others" represent the bacterial phyla with abundances of less than $0.01 \%$.

Gammaproteobacteria were more abundant in genus Sinularia than genus Sarcophyton. Mollicutes comprised 81.4\% of the total bacterial population in the GI_Sagl09 specimen, but was only $9.6 \%$ in the most highly abundant specimen DI_Siqu09 in the genus Sinularia. Gammaproteobacteria has a maximum abundance values of $72.6 \%$ and $17.1 \%$ in genus Sinularia and genus Sarcophyton respectively.

Totally identified bacterial were divided in 408 families (Figure 6) whereas 336 and 345 belonged to Sarcophyton and Sinularia, respectively. Spiroplasmataceae, Rhodobacteraceae, and Halomonadaceae are dominant flora with abundance percentages of $20.8 \%, 9.5 \%$, and $4.0 \%$, respectively. Rhodobacteracea is a potential pathogen of coral. In addition, the abundance of symbiotic bacteria showed high similarity in the same coral genus at the same sampling point. For example, Rhodobacteracea was most abundant in the genus Sarcophyton collected from Ximao Island, whereas Spiroplasmataceae were most abundant in genus Sarcophyton collected from Ganzhe Island. Unlike genus Sarcophyton, symbiotic bacteria in all specimens that were collected from Ximao Island and Ganzhe Island showed high diversity and do not contain major bacterial families.

PCoA analysis obviously showed seven separated groups (Figure 7). Although result cannot display a relationship between bacterial diversity and localities, it can be generally documented that in each locality bacterial characteristics of same coral species were clustered in separated group.

\section{Discussion}

At present, stony coral has been investigated by many experts for its unique reef-building capacity (Lee et al., 2012; Li et al., 2013; Li et al., 2014). Although soft corals have high potential medicinal value ( $\mathrm{Li}$ et al., 2019), there is no equivalent research report. This study collected two genera from three coral reefs of Ganzhe Island, Dazhou Island, and Ximao Island of Wanning City, Hainan Province, and a total of 23 soft coral specimens from nine species. A database of 23 commensal bacteria was obtained.

Significant differences in symbiotic bacteria in different species of stony corals have been confirmed (Hong et al., 2009). This study also found that this variability also exists in soft corals, and the three sea areas in this survey all showed this. There were significant differences in the abundance and diversity of symbiotic bacteria between different genera, but the differences in abundance and diversity of symbiotic bacteria in different species of a genus were not obvious (Table 2). The reason was unclear. Using the same method, Liang et al. (2017) found 55 bacteria phyla in 25 stone coral specimens, whereas in 23 soft coral specimens in this study, we detected 46 phyla. More bacterial symbiosis leads to greater uncertainty. Gardner et al. (2013) pointed out that for each additional species, the probability of instability increases by $2^{n-1}$. Pollock et al. (2019) found that the reduction of coral bacterial community is more beneficial to coral immune function. Although this finding does not prove that the gradual replacement of the coverage of stony corals by soft corals in the waters around Hainan Island was due to the existence of fewer symbiotic bacteria, the symbiotic relationship between bacteria and genus Sarcophyton or genus Sinularia was more stable than that of bacteria and stony corals.

Consistent with previous studies, the dominant symbiotic bacteria of soft corals in the South China Sea is Proteobacteria (39.99\%), but its abundance in soft 
Community barplot analysis

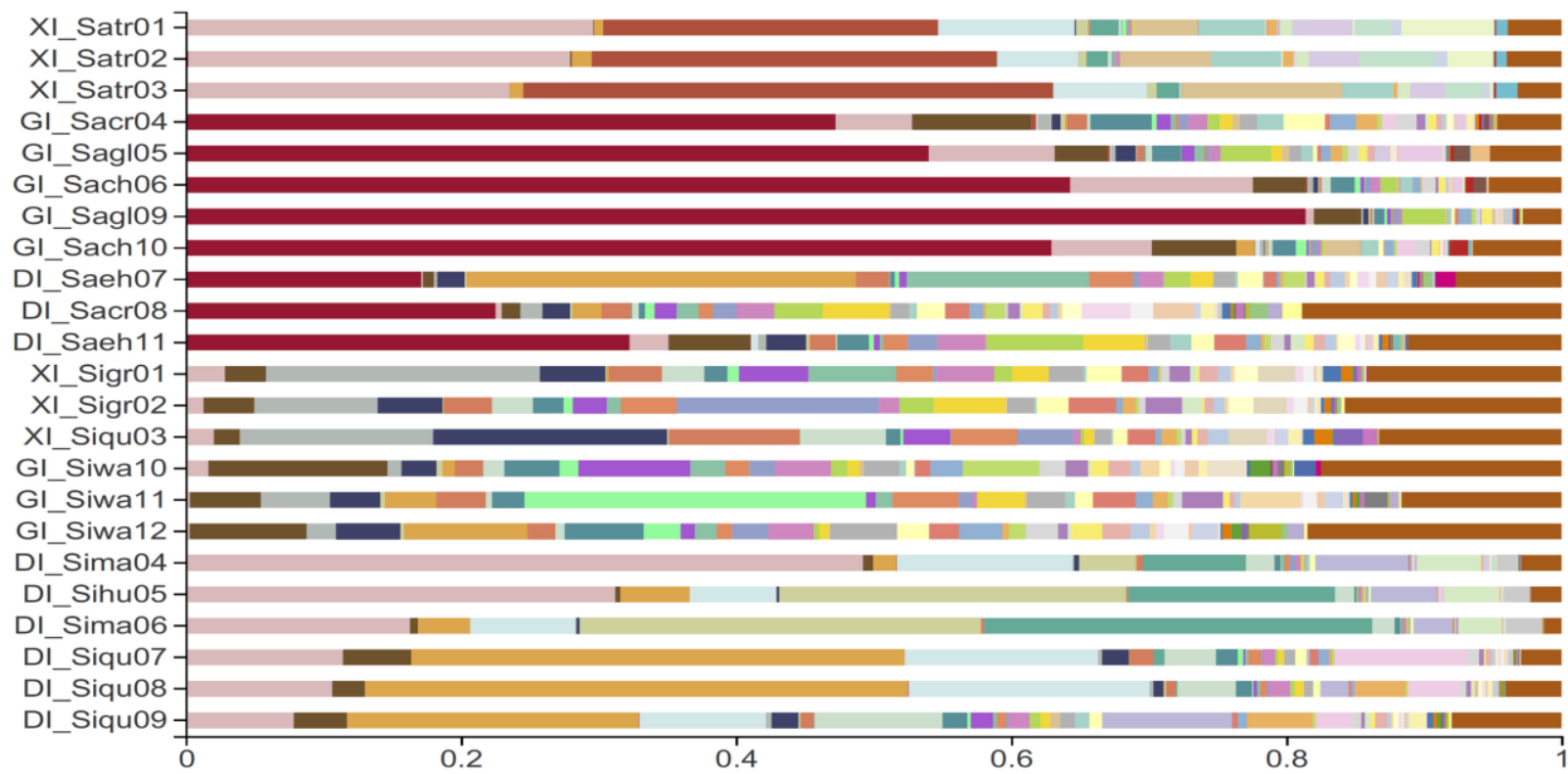

Percent of community abundance on Family level

\begin{tabular}{|c|c|c|c|c|}
\hline Spiroplasmataceae & Bacillaceae & Comamonadaceae & Streptococcaceae & norank_o__Mollicutes_RF9 \\
\hline Rhodobacteraceae & Moraxellaceae & Desulfovibrionaceae & Porphyromonadaceae & Salinisphaeraceae \\
\hline Halomonadaceae & norank_c_Cyanobacteria & Pseudomonadaceae & Ferrimonadaceae & Coriobacteriaceae \\
\hline Pseudoalteromonadaceae & Bacteroidales_S24-7_group & Oligoflexaceae & Pasteurellaceae & Microbacteriaceae \\
\hline Marinilabiaceae & Burkholderiaceae & Idiomarinaceae & Verrucomicrobiaceae & Oxalobacteraceae \\
\hline Vibrionaceae & Peptostreptococcaceae & Rikenellaceae & Thiotrichales_Incertae_Sedis & unclassified_P_Bacteroidetes \\
\hline Micrococcaceae & Spirochaetaceae & Campylobacteraceae & Kazan-2B-17 & Neisseriaceae \\
\hline Ruminococcaceae & Prevotellaceae & Aeromonadaceae & unclassified_k__norank & Actinomycetaceae \\
\hline Shewanellaceae & Phyllobacteriaceae & Clostridiaceae_1 & Xanthomonadaceae & MD3-55 \\
\hline Enterococcaceae & Enterobacteriaceae & Erysipelotrichaceae & Alteromonadaceae & Veillonellaceae \\
\hline Lachnospiraceae & Flavobacteriaceae & Family_XII_o__Clostridiales & Staphylococcaceae & [ Family_XII_o__Bacillales \\
\hline Oceanospirillaceae & Lactobacillaceae & Sphingomonadaceae & Christensenellaceae & Mitochondria \\
\hline Mycobacteriaceae & Mycoplasmataceae & Fusobacteriaceae & Coxiellaceae & others \\
\hline Dietziaceae & Bacteroidaceae & Entomoplasmatales_Incertae_Sedis & Flammeovirgaceae & \\
\hline
\end{tabular}

Figure 6. Bacterial composition profiles. Taxonomic classification of bacterial reads retrieved from different coral species on Family level. "others" represent the bacterial phyla with abundances of less than $0.01 \%$.

PCoA on OTU level

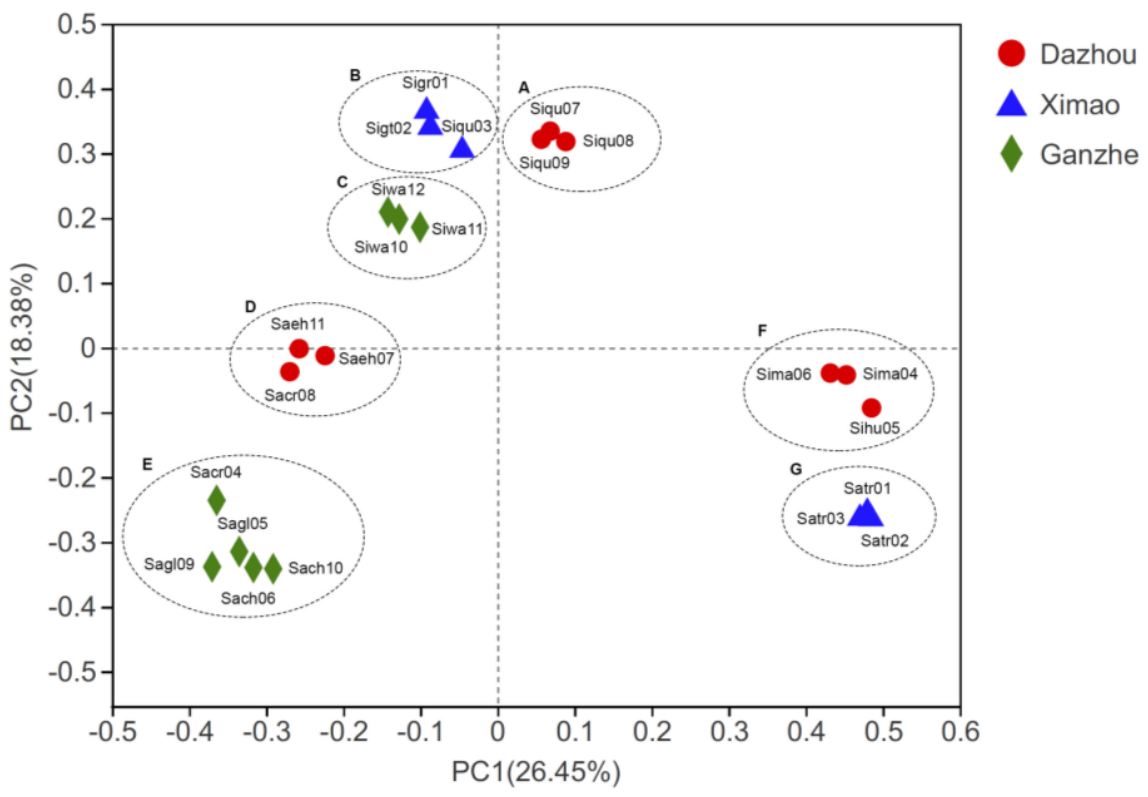

Figure 7. Principal co-ordinates analysis (PCOA) plot based on the OTU level from 25 coral species. The scatter plot is of principal coordinate 1 (PC1) vs. principal coordinate 2 (PC2). PC1 and PC2 represent the principal factors affecting bacterial composition associated with corals. 


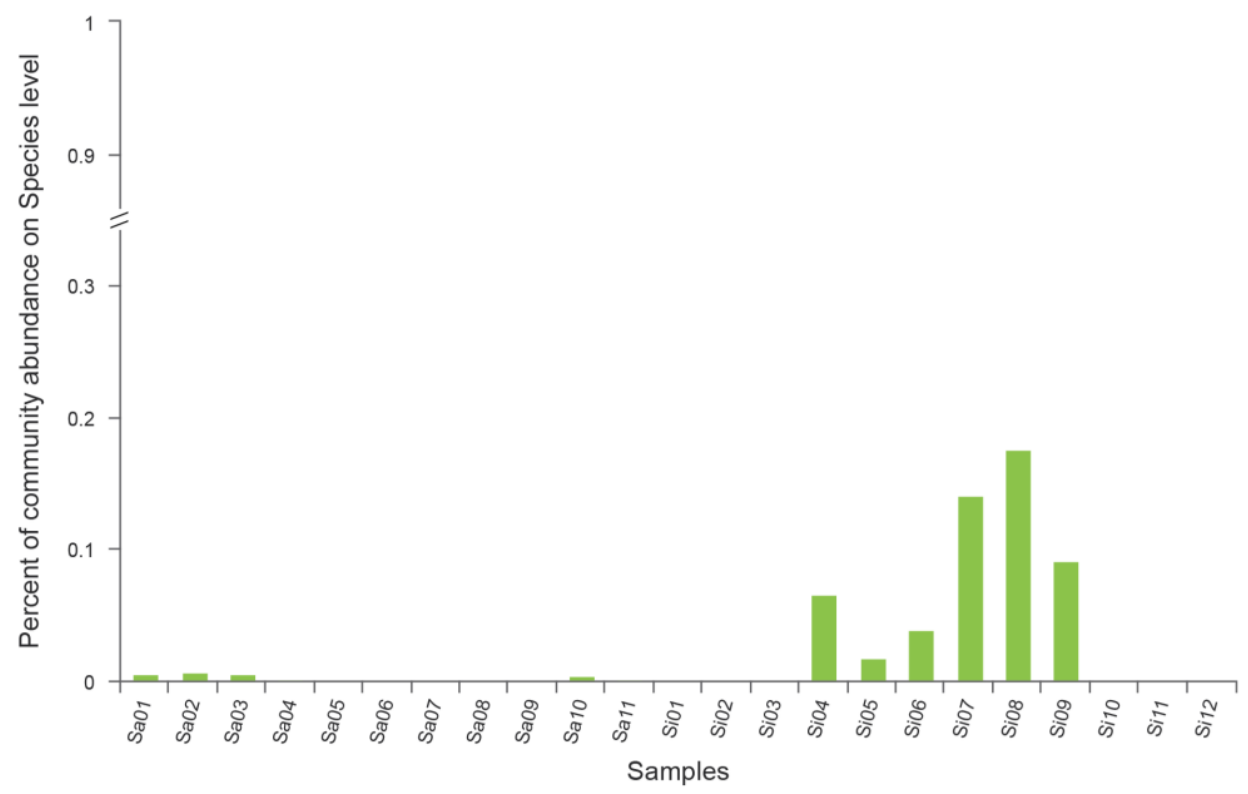

Figure S1. Vibrio fortis composition profiles.

corals is slightly lower than stony corals (52.56\%). Compared with previous studies on symbiotic bacteria of stony corals, the presence of a large number of Tenericutes in the soft corals of the genus Sarcophyton genus has not been reported in studies on coral symbiotic bacteria near Hainan Island (Figure 4). Weiler et al. (2018) argue that Teneriquets has a relationship with cold-water corals that play an important role in the nitrogen cycle. However, in the genus Sinularia of the same waters, the abundance of such bacteria was lower, and even some species did not contain Teneriquets. At the same time, we found a large number of Vibrio fortis in the Sinularia genus in Dazhou Island (Figure S1). Many Vibrio species are considered to be potential coral pathogens, such as Vibrio shiloi (Kushmaro, Fine, \& Rosenberg, 1966), Vibrio coralliilyticus (Ben-Haim, Zicherman-Keren, \& Rosenberg, 2003), Vibrio carchariae (Ritchie \& Smith, 1995), and Vibrio alginolyticus (Cervino et al., 2004). However, no report has indicated that $V$. fortis is also a coral pathogen. García-Amado et al. (2011) also confirmed that $V$. fortis is a common bacteria in seawater living at specific depths and a natural component of microbial community in marine redox environments. Sarcophyton and Sinularia have their own symbiotic bacteria, which are different from those of stony coral, thereby providing a theoretical basis for the further study of the genetic evolution of soft corals.

Chan et al. (2019) found that different coral species have different bacterial community, and environmental conditions are the main driving forces for early coral microbial community. This study confirmed that the same genus or the same species of soft corals that had different geographical locations, contained various bacterial community. Unlike the previous results on the genus Sarcophyton in the Red Sea (Lee et al., 2012), Endozoicomonas is not a dominant bacterial species and has low abundance among the Sarcophyton corals in the waters around Hainan. Symbiotic zooxanthellae can affect the abundance of Endozoicomonas (Pantos et al., 2015), and the composition of different zooxanthellae may be one of the causes of this variation. The impact of different geographical environments on coral symbiotic bacteria is multifaceted. First, Woo et al. (2017) believed that differences in latitude are potential causes of coral symbiotic bacteria diversity. When latitude changes exceed $10^{\circ}$, it should be considered as an important factor affecting the results. In this study, the three sampling points are located near the $18^{\circ}$ north latitude, which we believe is no longer a factor affecting the bacteria. Secondly, the composition of coral-associated bacteria is influenced by temperature and season (Hong et al., 2009). Based on the sampling time concentrated in September, a temperature difference of $2{ }^{\circ} \mathrm{C}$ exists between the temperatures at the Sanya sampling point and that at Wanning sampling point, which may lead to the richness in symbiotic bacteria in cold water corals, such as Tenericums, as seen in the specimens from Dazhou Island and Ganzhe Island.

In a specific area, the unique breeding of corals often affects their symbiotic bacterial community. For example, Stylophora pistillata allows microorganisms to be transferred vertically from the parent to the offspring (Sharp, Distel, \& Paul, 2012). Human activities, such as diving and fisheries, are also factors that influence the microbial composition of coral reef ecosystems (Kelly et al., 2014). However, we are not sure whether these incentives are direct factors influencing the geographical differences in soft coral symbiotic bacteria. Thus, direct experimental evidence is needed. Future studies on soft coral-associated microbes should consider host reproductive strategies, metabolites, and environmental factors.

In conclusion, although each locality represents special bacterial diversity, same coral species in each locality represent similar pattern of bacterial community. 


\section{Acknowledgments}

This work was supported by Hainan Province Science and Technology Department Key Research and Development Program (ZDYF2019154).

\section{References}

Ben-Haim, Y., Zicherman-Keren, M., \& Rosenberg, E. (2003). Temperature regulated bleaching and lysis of the coral Pocillopora damicornis by the novel pathogen Vibrio coralliilyticus. Applied and Environmental Microbiology, 69, 4236-4242.

https://doi.org/10.1128/AEM.69.7.4236-4242.2003

Bolger, A.M., Lohse, M., \& Usadel, B. (2014). Trimmomatic: a flexible trimmer for Illumina sequence data. Bioinformatics, 30, 2114-2120.

https://doi.org/10.1093/bioinformatics/btu170

Cervino, J.M., Hayes, R.L., Polson, S.W., Polson, S.C., Goreau, T.J., Martinez, R.J., \& Smith G. (2004). Relationship of Vibrio species infection and elevated temperatures to yellow blotch/band disease in Caribbean corals. Applied and Environmental Microbiology, 70, 6855-6864. https://doi.org/10.1128/10.1128/AEM.70.11.68556864.2004

Chan, W.Y., Peplow, L.M., Menéndez, P., Hoffmann, A.A., \& van-Oppen, M.J.H. (2019). The roles of age, parentage and environment on bacterial and algal endosymbiont community in Acropora corals, 28, 3830-3843. https://doi.org/10.1111/mec.15187

García-Amado, M.A., Bozo-Hurtado, L., Astor, Y., Suárez, P., \& Chistoserdov, A. (2011). Denaturing gradient gel electrophoresis analyses of the vertical distribution and diversity of Vibrio spp. populations in the Cariaco Basin. FEMS Microbiology Ecology, 77, 347-56. https://doi.org/10.1111/j.1574-6941.2011.01116.x

Gardner, M.R., \& Ashby, W.R. (1970). Connectance of large dynamic (cybernetic) systems: critical values for stability. Nature, 228, 784. https://doi.org/10.1038/228784a0

Guest, J.R., Low, J., Tun, K., Wilson, B., Raingeard, C.N.D., Ulstruo, K.E., Tanzil, J.T.I., Todd, P., Toh, T.C., Mcdougald, D., Chou, L.M., \& Steinberg, P. (2016). Coral community response to bleaching on a highly disturbed reef. Scientific Reports, 6, 20717. https://doi.org/10.1038/srep20717

Hassan, H.M., Rated, M.E., Hassan, M.H., Sayed, A.M., Shabana, S., Raslan, M., Amin, E., Behery, F.A., Ahmed, O.M., Muhsinah, A.B., Gulder, T.A.M., \& Abdelmohsen, U.R. (2019). New antiproliferative cembrane diterpenes from the Red Sea Sarcophyton species. Marine Drugs, 17(7), 411. https://doi.org/10.3390/md17070411

Hong, M.J., Yu, Y.T., Chen, C.A., Chiang, P.W., \& Tang, S.L. (2009). Influence of species specificity and other factors on bacteria associated with the coral Stylophora pistillata in Taiwan. Applied and Environmental Microbiology, 75, 7749-7806. https://doi.org/10.1128/AEM.01418-09

Kelly, L.W., Williams, G.J., Barott, K.L., Carlson, C.A., Dinsdale, E.A., Edwards, R.A., Haas, A.F., Haynes, M., Lim, Y.W., McDole, T., Nelson, C.E., Sala, E., Sandin, S.A., Smith, J.E., Vermeij, M.J.A., Youle, M., \& Rohwer, F. (2014). Local genomic adaptation of coral reef-associated microbiomes to gradients of natural variability and anthropogenic stressors. PNAS, 111, 10227-10232. https://doi.org/10.1073/pnas.1403319111

Kuczynski, J., Stombaugh, J., Walters, W.A., González, A., Caporaso, J.G., \& Knight, R. (2012). Using QIIME to analyze 16S rRNA gene sequences from microbial community. Current Protocols in bioinformatics, 10(7), 10. https://doi.org/10.1002/0471250953.bi1007s36

Kushmaro, A., Fine, L.M., \& Rosenberg, E. (1966). Bacterial infection and coral bleaching. Nature, 380, 396. https://doi.org/10.1038/380396a0.

Lee, O.O., Yang, J., Bougouffa, S., Wang, Y., Batang, Z., Tian, R., Al-Suwailem, A., \& Qian, P.Y. (2012). Spatial and species variations in bacterial community associated with corals from the Red Sea as revealed by pyrosequencing. Applied and Environmental Microbiology, 78, 71737184. https://doi.org/10.1128/aem.01111-12

Lesser, M.P., Mazel, C.H., Gorbunov, M.Y., \& Falkowski, P.G. (2004). Discovery of symbiotic nitrogen-fixing cyanobacteria in corals. Science, 305, 997-1000. https://doi.org/10.1126/science.1099128

Li, J., Chen, Q., Long, L.J., Dong, J.D., Yang, J., \& Zhang, S. (2014). Bacterial dynamics within the mucus, tissue and skeleton of the coral Porites lutea during different seasons. Scientific Reports, 4, 7320. https://doi.org/10.1038/srep07320

Li, J., Chen, Q., Zhang, S., Huang, H., Yang, J., Tian, X.P., \& Long, X.P. (2013). Highly heterogeneous bacterial community associated with the South China Sea reef corals Porites lutea, Galaxea fascicularis and Acropora millepora. PLOS ONE, 8, e71301. https://doi.org/10.1371/journal.pone.0071301

Li, T., Wang, N., Zhang, T., Zhang, B., Sajeevan, T.P., Joseph, V., Armstrong, L., He, L., Yan, X.J., \& Naman, C.B. (2019). A systematic review of recently reported marine derived natural product kinase inhibitors. Marine Drugs, 17, 493. https://doi.org/10.3390/md17090493

Liang, J.Y., Yu, K.F., Wang, Y.H., Huang, X.Y., Huang, W., Qin, Z.J., Pan, Z.L., Yao, Q.C., Wang, W.H., \& Wu, Z.C. (2017). Distinct bacterial community associated with massive and branching scleractinian corals and potential linkages to coral susceptibility to thermal or cold stress. Frontiers in Microbiology, 8, 1-10. ttps://doi.org/10.3389/fmicb.2017.00979

Mahmoud, H.M., \& Kalendar, A.A. (2016). Coral-Associated Actinobacteria: Diversity, Abundance, and Biotechnological Potentials. Frontiers in Microbiology. 7, 204. https://doi.org/10.3389/fmicb.2016.00204

Mao-Jones, J., Ritchie, K.B., Jones, L.E., \& Ellner, S.P. (2010). How Microbial community composition regulates coral disease development. PLoS Biology, 8(3), e1000345. https://doi.org/10.1371/journal.pbio.1000345

McKew, B.A., Dumbrell, A.J., Daud, S.D., Hepburn, L., Thorpe, E., Mogensen, L., \& Whitby, C. (2012). Characterization of geographically distinct bacterial community associated with coral mucus produced by Acropora spp. and Porites spp. Applied and Environmental Microbiology, 78(15), 5229-5237. https://doi.org/10.1128/AEM.07764-11

Merrifield, D.L., Dimitroglou, A., Foey, A., Davies, S.J., Baker, R.T.M., Bøgwald, J., Castex, M., \& Ring $\varnothing$, E. (2010). The current status and future focus of probiotic and prebiotic applications for salmonids. Aquaculture, 302, 1-18. https://doi.org/10.1016/j.aquaculture.2010.02.007

Mori, H., Maruyama, F., Kato, H., Toyoda, A., Dozono, A., Ohtsubo, Y., Fujiyama, A., Tsuda, M., \& Kurokawa, K. (2014). Design and experimental application of a novel 
non-degenerate universal primer set that amplifies prokaryotic $16 \mathrm{~S}$ rRNA genes with a low possibility to amplify eukaryotic rRNA genes. DNA Research, 21(2), 217-227. https://doi.org/10.1093/dnares/dst052

Neulinger, S.C., Järnegren, J., Ludvigsen, M., Lochte, K., \& Dullo, W.C. (2008). Phenotype-specific bacterial communities in the cold-water coral Lophelia pertusa (Scleractinia) and their implications for the coral's nutrition, health, and distribution. Applied and Environmental Microbiology, 74, 7272-7285. https://doi.org/10.1128/AEM.01777-08

Pantos, O., Bongaerts, P., Dennis, P.G., Tyson, G.W., \& HoeghGuldberg, O. (2015). Habitat-specific environmental conditions primarily control the microbiomes of the coral Seriatopora hystrix. ISME J, 9,1916-1927. https://doi.org/10.1038/ismej.2015.3

Pollock, F.J., Lamb, J.B., Van-de-Water, J.A.J.M., Smith, H.A., Schaffelke, B., Willis, B.L., \& Bourne, D.G. (2019). Reduced diversity and stability of coral-associated bacterial community and suppressed immune function precedes disease onset in corals. Royal Society Open Science, 6, 190355.

https://doi.org/10.1098/rsos.190355

Quast, C., Pruesse, E., Yilmaz, P., Gerken, J., Schweer, T., Yarza, P., Peplies, J., \& Glöckner, F.O. (2013). The SILVA ribosomal RNA gene database project: improved data processing and web-based tools. Nucleic Acids Research, 41, 590-596. https://doi.org/10.1093/nar/gks1219

Ritchie, K.B., \& Smith, G.W. (1995). Preferential carbon utilization by surface bacterial community from water mass, normal, and white-band diseased Acropora cervicornis. Molecular marine biology and biotechnology, 4(4), 345-352.

Rosenberg, E., Koren, O., Reshef, L., Efrony, R., \& ZilberRosenberg, I. (2009). The role of microorganisms in coral health, disease and evolution. Nature Reviews Microbiology, 5, 355-362. https://doi.org/10.1038/nrmicro1635

Sang, V.T., Dat, T.T.H., Vinh, L.B., Cuong, L.C.V., Oanh, P.T.T., Ha, H., Kim, Y.H., Anh, Y.H., \& Yang, S.Y. (2019). Coral and coral-sssociated microorganisms: a prolific source of potential bioactive natural products. Marine Drugs, 17(8), 468. https://doi.org/10.3390/md17080468

Schloss, P.D., Gevers, D., \& Westcott, S.L. (2011). Reducing the Effects of PCR Amplification and sequencing artifacts on 16S rRNA-based studies. PLoS One, 6, e27310. https://doi.org/10.1371/journal.pone.0027310
Woo, S., Yang, S.H., Chen, H.J., Tseng, Y.F., Hwang, S.J., Palmas, S.D., Vianney, D., Yukimitsu, I., Fumihito, I., Seungshic, Y., \& Tang, S.L. (2017). Geographical variations in bacterial community associated with soft coral Scleronephthya gracillimum. PLoS One, 12, e0183663. https://doi.org/10.1371/journal.pone.0183663

Sharp, K.H., Distel, D., \& Paul, V.J. (2012). Diversity and dynamics of bacterial community in early life stages of the Caribbean coral Porites astreoides. ISME J, 6, 790801.

Seonock, W., Shan-Hua, Y., Hsing-Ju, C., Yu-Fang, T., Sung-Jin, H., Stephane, D.P., Vianney, D., Yukimitsu, I., Fumihito, I., Seungshic, Y., \& Sen-Lin, T. (2017). Geographical variations in bacterial communities associated with soft coral Scleronephthya gracillimum. PLOS ONE, 12, e0183663. https://doi.org/10.1371/journal.pone.0183663

Teplitski, M., \& Ritchie, K. (2009). How feasible is the biological control of coral diseases. Trends in Ecology and Evolution, 24(7), 378-85. https://doi.org/10.1016/j.tree.2009.02.008

Thurber, R.V., Willner-Hall, D., Rodriguez-Mueller, B., Desnues, C., Edwards, R.A., \& Angly, F. (2009) Metagenomic analysis of stressed coral holobionts. Environmental Microbiology, 11(8), 2148-2163. https://doi.org/10.1111/j.1462-2920.2009.01935.x

Weiler, B.A., Verhoeven, J.T.P., \& Dufour, S.C. (2018). Bacterial community in tissues and surficial mucus of the coldwater coral Paragorgia arborea. Frontiers in Marine Science, 5, 378. https://doi.org/10.3389/fmars.2018.00378

Xu, N., Tan, G., Wang, H., \& Gai, X. (2016). Effect of biochar additions to soil on nitrogen leaching, microbial biomass and bacterial community structure. European Journal of Soil Biology, 74, 1-8.

https://doi.org/10.1016/j.ejsobi.2016.02.004

Yu, Z.C., Liu, C., Fu, Q., Lu, G.X., Han, S., Wang, L.L., \& Song, L.S. (2019). The differences of bacterial community in the tissues between healthy and diseased Yesso scallop (Patinopecten yessoensis). AMB Express, 9(1), 148. https://doi.org/10.1186/s13568-019-0870-x

Zhou, Y., Yang, C.J., Wang, P.Z., Wang, H.S., Xu, X.S., \& Li, W.D. (2019). Identification of the soft coral genera Sarcophyton in the coastal waters of Hainan Island. Journal of Applied Oceanography, 38, 33-45. https://doi.org/10.3969/J.ISSN.2095-4972.2019.01.004 